
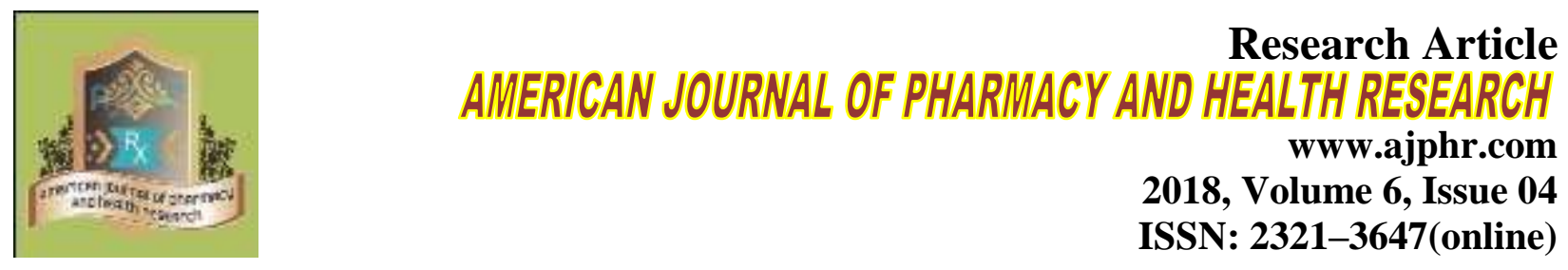

\title{
Spectrophotometric Determination of Procainamide by Charge- Transfer Complexation
}

\author{
B. Eswara Naik ${ }^{1,3}$, C. Narasimha Rao ${ }^{2}$, S. Ramanaiah ${ }^{1}$ and P. Venkateswarlu ${ }^{2 *}$ \\ 1 Department of Chemistry, Rayalaseema University, Kurnool, 518002, Andhra Pradesh, India. \\ 2. Department of Chemistry, S. V. University, Tirupati, 517502, Andhra Pradesh, India. \\ 3. Department of Chemistry, IIIT-R.K.Valley, RGUKT-A.P., Kadapa, 516330, Andhra Pradesh, \\ India.
}

\begin{abstract}
A simple and sensitive spectrophotometric method has been developed for the determination of procainamide (PA) in pure and pharmaceutical formulations. The proposed method is based on the formation of charge-transfer complex between the drug and 1-chloro-2, 4-dinitrobenzene (CDNB). PA in the presence of CDNB formed yellowish red colored complex, which showed a maximum absorbance at $410 \mathrm{~nm}$. The limit of detection and quantitation were $0.1183 \mathrm{mg} / \mathrm{ml}$ and $0.3940 \mathrm{mg} / \mathrm{ml}$ respectively. The influence of commonly used excipients on the determination of PA was studied.
\end{abstract}

Keywords: Spectrophotometric method, Procainamide, CDNB, Charge-transfer complex. 


\section{INTRODUCTION}

Procainamide (PA); 4-amino-N-(2-diethylaminoethyl) benzamine, (Figure. 1) is used to prevent atrial and ventricular arrhythmias. It is known to induce a voltage-dependent open channel block on the Bactra Cho toxin (BTX)-activated sodium channels in cardiomyocytes ${ }^{1,2}$. Several methods have been reported for the determination of the PA. These methods include pharmacopoeial methods ${ }^{3,4}$, titrimetry $^{5,6}$, colorimetry ${ }^{7,8}$, spectrophotometry ${ }^{9-14}$, fluorometry ${ }^{15}$ and chromatograph $^{16-18}$. The survey of literature has shown that no spectrophotometric method was reported so far, for the determination of PA with CDNB.

In present investigation, a new spectrophotometric method has been developed that is simple, accurate and reproducible for the determination of PA based on the formation of charge-transfer complex reaction with CDNB to give colored solution and can be used for the determination of PA in bulk and its formulations.

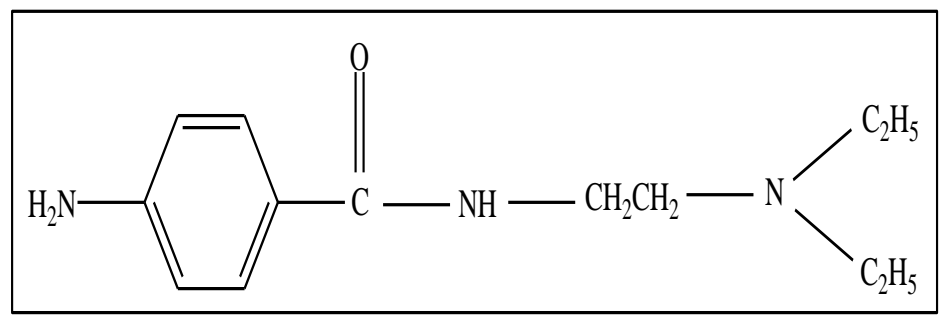

Figure 1: Structure of PA

\section{EXPERIMENTAL}

\section{Instrumentation}

A Shimadzu UV-Visible spectrophotometer (UV-160A) with a matched pair of $10 \mathrm{~mm}$ quartz cells was utilized for all measurements. Mettler Toledo analytical balance (accuracy $0.1 \mathrm{mg}$ ) was used for weighing all the samples.

\section{Materials and Reagents}

PA was procured from Sigma-Aldrich. Formulations were purchased from local market. All the chemicals used were of analytical reagent grade. Double distilled water is used throughout the experiment. A stock solution of PA was prepared by dissolving accurately weighed $100 \mathrm{mg}$ of pure drug in $100 \mathrm{ml}$ of water and sonicated to get required concentration of $1 \mathrm{mg} / \mathrm{ml}$. Further, it was diluted with double distilled water as required for the present investigation.

RESULTS AND DISCUSSION

\section{Absorption spectrum}


Different aliquots of standard PA were taken in a several volumetric flasks, added $2 \mathrm{ml}$ of $3 \%$ CDNB reagent heated the entire content to $98 \pm 2^{\circ} \mathrm{C}$. At this temperature yellowish red color chromogen was formed, which shows a maximum absorbance at $410 \mathrm{~nm}$ against the blank reagent (Figure. 2).

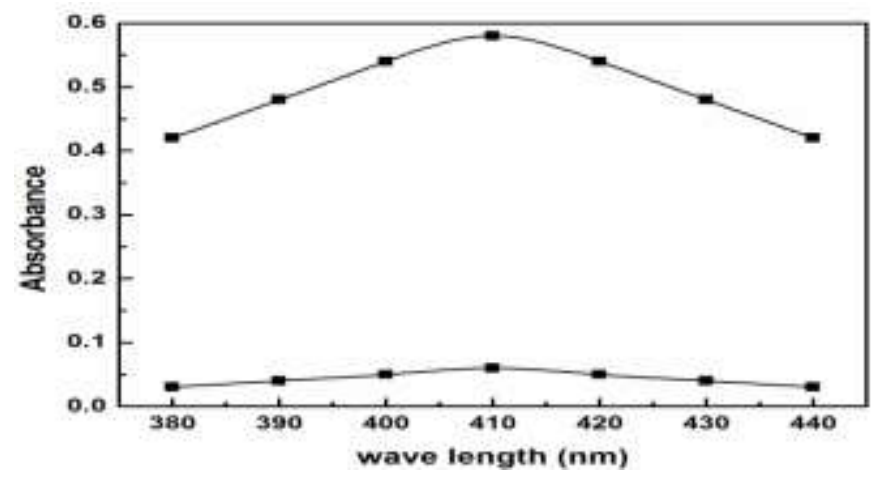

Figure 2: Absorption Spectrum of PA With CDNB

\section{Effect of reagent CDNB concentration}

The effect of CDNB reagent concentration was found that $2 \mathrm{ml}$ of $3 \%$ CDNB produced maximum intensity of chromogen that was unaffected by further addition of few drops of reagent. Therefore $2 \mathrm{ml}$ of CDNB reagent solution was used for further study.

\section{Effect of Drug Concentration}

Various concentrations of PA were taken in volumetric flasks in the range of $4-30 \mu \mathrm{g} / \mathrm{ml}$ and CDNB reagent was added to each flask. The maximum absorbance was measured at $410 \mathrm{~nm}$.

\section{ANALYTICAL METHOD VALIDATION}

\section{Linearity}

The linearity of an analytical method is its ability to elicit test results that are directly proportional to the concentration of analyte in samples within a given range (Figure. 3). The linearity of calibration graphs was proved by the high values of the correlation coefficient and small values of the y-intercept of the regression equation. The apparent molar absorptivity of the resulting colored complexes and relative standard deviation of response factors for the proposed spectrophotometric method were also calculated and obtained results like Beer's law limit, Sandal's sensitivity and molar absorptivity are reported in Table 1. 


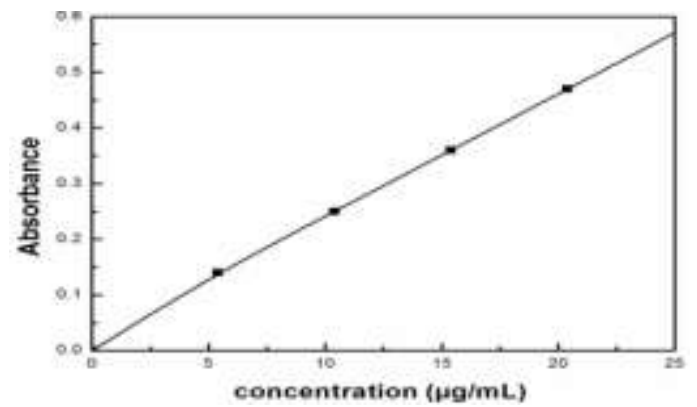

Figure 3: Calibration plot of PA

Table 1: Spectral characteristics of the drug with reagent

\begin{tabular}{lllllllllll}
\hline $\begin{array}{l}\lambda \text { max } \\
(\mathbf{n m})\end{array}$ & $\begin{array}{l}\text { Beer's } \\
\text { law limit } \\
(\boldsymbol{\mu g} / \mathbf{m l})\end{array}$ & $\begin{array}{l}\text { Molar } \\
\text { absorbance } \\
\left(\mathbf{L . m o l} \mathbf{- 1}^{-1}\right.\end{array}$ & $\begin{array}{l}\text { Sandell's } \\
\text { sensitivity }\end{array}$ & $\begin{array}{l}\text { Correlation } \\
\text { coefficient } \\
\left(\mathbf{r}^{\mathbf{2}}\right)\end{array}$ & $\begin{array}{l}\text { Slope } \\
(\mathbf{m})\end{array}$ & $\begin{array}{l}\text { Intercept } \\
(\mathbf{c})\end{array}$ & \%RSD & Colour & LOD & LOQ \\
410 & $6-27$ & $2.698 \times 10^{4}$ & 0.0017 & 0.9925 & 0.254 & 0.0447 & 0.1724 & $\begin{array}{l}\text { Yellowish } \\
\text { Red }\end{array}$ & 0.1183 & 0.3940 \\
\hline
\end{tabular}

\section{Robustness and ruggedness}

During the evaluation of robustness, some parameters like concentration of drug and reagent, wavelength range and shaking time were interchanged. The capacity remains unaffected by small deliberate and shaking time. Method ruggedness was expressed as \% RSD of the same procedure applied by two analysts and in two different instruments on different days. The results showed no statistical difference between different analysts and instruments suggesting that the developed methods were robust and rugged.

\section{Accuracy}

It is defined as agreement between the true value and obtained value. The obtained accuracy results were proved that, the recovery percentage values in drug and in pharmaceutical formulations were within the acceptance criteria and details were presented in Table 2 and 3.

Table 2:Evaluation of accuracy and precision results of the proposed method in bulk form

\begin{tabular}{lllllllll}
\hline $\begin{array}{l}\text { Taken } \\
\text { mg/ml }\end{array}$ & $\begin{array}{l}\text { Intra day } \\
\text { *Found mg/ml }\end{array}$ & Recovery \% & $\mathbf{\pm}$ SD & \% RSD & $\begin{array}{l}\text { Inter day } \\
\text { *Found mg/ml }\end{array}$ & Recover \% & $\mathbf{\pm}$ SD & \% RSD \\
\hline 2 & 1.98 & 98.83 & 0.006 & 0.29 & 1.99 & 99.33 & 0.006 & 0.29 \\
4 & 3.96 & 99.08 & 0.006 & 0.15 & 3.96 & 99.00 & 0.017 & 0.44 \\
6 & 5.96 & 99.33 & 0.010 & 0.17 & 5.93 & 98.83 & 0.044 & 0.74 \\
\hline
\end{tabular}

*Average of six determinations

Table 3: Evaluation of accuracy and precision results of the proposed method in pharmaceutical dosage form

\begin{tabular}{|c|c|c|c|c|c|c|c|c|c|}
\hline $\begin{array}{l}\text { Pharmaceutical } \\
\text { formulation }\end{array}$ & $\begin{array}{l}\text { Taken } \\
\text { mg/ml }\end{array}$ & $\begin{array}{l}\text { Intra day } \\
\text { *Found } \\
\text { mg/ml }\end{array}$ & $\begin{array}{l}\text { Recovery } \\
\%\end{array}$ & $\pm \mathrm{SD}$ & $\begin{array}{l}\% \\
\text { RSD }\end{array}$ & $\begin{array}{l}\text { Inter day } \\
\text { *Found } \\
\text { mg/ml }\end{array}$ & Recovery\% & $\pm \mathrm{SD}$ & $\begin{array}{l}\% \\
\text { RSD }\end{array}$ \\
\hline pronestyl & 4 & 3.97 & 99.33 & 0.006 & 0.15 & 3.94 & 98.50 & 0.010 & 0.25 \\
\hline www.ajphr.com & & & & & & & & & 68 \\
\hline
\end{tabular}




\begin{tabular}{llllllllll}
\hline procanbid & 6 & 5.93 & 98.83 & 0.070 & 1.18 & 5.96 & 99.33 & 0.010 & 0.17 \\
pronestyl-SR & 8 & 7.96 & 99.54 & 0.015 & 0.19 & 7.94 & 99.29 & 0.025 & 0.32 \\
\hline \multicolumn{8}{c}{ *Average of six determinations }
\end{tabular}

\section{Precision}

Precision of a method is a measure of the ability to create reproducible results. It is evaluated using six separate determinations. The intra and inter day precision were evaluated and found $\%$ RSD is less than 1.0, that indicates that there was no significant variations for intra and inter day analysis and results were presented in Table 2 and 3.

\section{Limit of Detection (LOD)}

The detection limit of an individual analytical procedure is the lower amount of analyte in a sample that can be detected but not necessarily quantitated as an exact value.

The LOD was calculated by using the following formula.

$$
L O D=\frac{3.3 \mathrm{~s}}{\mathrm{~S}}
$$

Where, $\mathrm{s}=$ Standard deviation

$$
\mathrm{S}=\text { Slope of the calibration curve }
$$

\section{Limit of Quantitation (LOQ)}

The Quantitation limit of an individual analytical procedure is the lowest amount of analyte in a sample which can be quantitatively determined with suitable precision and accuracy.

The LOQ was calculated by using the following formula.

$$
L O Q=\frac{10 \mathrm{~s}}{\mathrm{~S}}
$$

where, $\mathrm{s}=$ Standard deviation

$$
\mathrm{S}=\text { Slope of the calibration curve }
$$

\section{APPLICATIONS}

Blood and urine samples were collected from healthy volunteers. The samples were centrifuged at $3000 \mathrm{rpm} \mathrm{min}{ }^{-1}$ for $10 \mathrm{~min}$. The solutions were filtered and preserved in the absence of light at $4^{0} \mathrm{C}$. To this, various concentrations of PA were added and analyzed with the developed method. The results are given in Table 4. High accuracy and good recoveries were obtained which indicate that the proposed method can be successfully applied to recover PA in urine and blood samples.

Table 4: Method accuracy from recovery studies

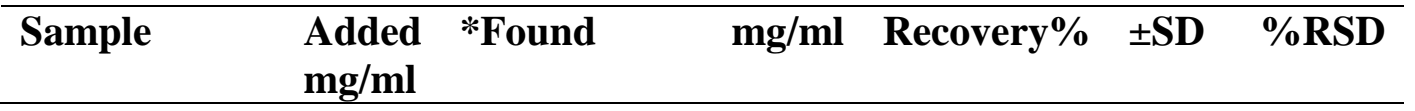




\begin{tabular}{|c|c|c|c|c|c|}
\hline \multirow[t]{4}{*}{ Blood samples } & 0.2 & 0.20 & 98.33 & 0.002 & 0.78 \\
\hline & 0.4 & 0.40 & 99.42 & 0.002 & 0.38 \\
\hline & 0.6 & 0.60 & 99.33 & 0.002 & 0.29 \\
\hline & 0.8 & 0.79 & 98.96 & 0.003 & 0.32 \\
\hline \multirow[t]{4}{*}{ Urine samples } & 0.4 & 0.40 & 99.33 & 0.001 & 0.29 \\
\hline & 0.6 & 0.60 & 99.22 & 0.001 & 0.10 \\
\hline & 0.8 & 0.79 & 99.17 & 0.003 & 0.39 \\
\hline & 1.0 & 0.98 & 98.00 & 0.010 & 1.02 \\
\hline
\end{tabular}

*Average of six determinations

\section{CONCLUSION}

In the current developed method, the drug PA was estimated in bulk, in pharmaceutical formulations and in biological fluid samples. The developed method is simple, accurate, precise and reproducible.

\section{REFERENCES}

1. Osadchii OE. Procainamide and lidocaine produce dissimilar changes in ventricular repolarization and arrhythmogenicity in guinea-pig. Fundam. Clin. Pharmacol. 2014; 23: 382-393

2. Zamponi GW, Sui X, Codding PW, French RJ. Dual actions of procainamide on batrachotoxin-activated sodium channels, open channel block and prevention of inactivation. Biophys J. 1993; 65: 2324-2334.

3. Roden DM. Antiarrhythmic effects efficacy, pharmacokinetics and safety of Nacetylprocainamide in huma subjects: Comparison with procainamide. Am. J. Cadiol. 1980; 46: 463-468.

4. Krebs C. Procainamide pharmacokinetics and diuretic and fluid administration. J. Am. Coll. Cardiol. 1987; 9: 247.

5. Harold K. Interference by traces of acetic anhydride in non aqueous titrimetric of primary aromatic amines: Improved titrations for procainamide hydrochloride. J. Pharm. Sci. 1974; 63: 919-923.

6. Blake MI, Bode DW, Rhodes HJ. Non aqueous titration of procainamide hydrochloride. J. Pharm. Sci. 1974; 63: 1645-1646.

7. Whitaker JE, Hoyt Jr AM. Colorimetric determination of procainamide in injectable preparations. J. Pharm. Sci. 1984; 73: 1184-1185.

8. Henry SIT, Shelton D. Colorimetric analysis of procaine hydrochloride. J. Pharm. Sci. 1974; 63: 916-919. 
9. Hamm JC. Collaborative study of the spectrophotometric determination of procainamide hydrochloride. J. Assoc. Off. Anal. Chem. 1976; 59: 807-810.

10. Al-Tamrah S, Al-Abbad S. Spectrophotometric determination of procainamide hydrochloride using sodium periodate. Arabian. J. Chem. 2015; 8: 609-613.

11. Johnson OO, Paul DD. Spectrophotometric determination of procainamide by chargetransfer complexation with chloranilic acid. J. Pharm. Bioresour. 2004; 1: 35-40.

12. Sterling JM, Haney WG. Spectrophotometric analysis of procainamide and sulfadiazine in presence of primary aliphatic amines based on reaction with fluorescamine. J. Pharm. Sci. 1974; 63: 1448-1450.

13. Sastry CSP, Rao TT, Sailaja A, Thirupathi Rao T. Spectrophotometric method for the determination of procainamide hydrochloride in tablets. Indian J. Pharm. Sci. 1991; 53: 249-251.

14. Mahamed AM, Hassan HY, Mohamed HA, Hussein SA. Use of 7,7,8,8Tetracyanoquinodimethane for spectrophotometric determination of certain local anaesthetics and procainamide. J. Pharm. Biomed. Anal. 1991; 9: 525-530.

15. TTan HS, Beiser C. Rapid fluorometric determination of procainamide hydrochloride dosage forms. J. Pharm. Sci. 1975; 64: 1207-1210.

16. Raphanaud D, Borensztejn M, Dupeyron JP, Guyon F. High performance liquid chromatography of procainamide and $\mathrm{N}$-acetylprocainamide in human blood plasma. Ther. Drug. Monit. 1986; 8: 365-367.

17. Sukur LR, Powers JL, Marques RA, Winter ME, Sadee W. Measurement of procainamide and $\mathrm{N}$-acetylprocainamide in serum by high-performance liquid chromatography. Clin. Chem. 1977; 23: 636-638.

18. Patel CP. Improved liquid chromatographic determination of procainamide and Nacetylprocainamide in serum. Ther. Drug. Monit. 1983; 5: 235-238.

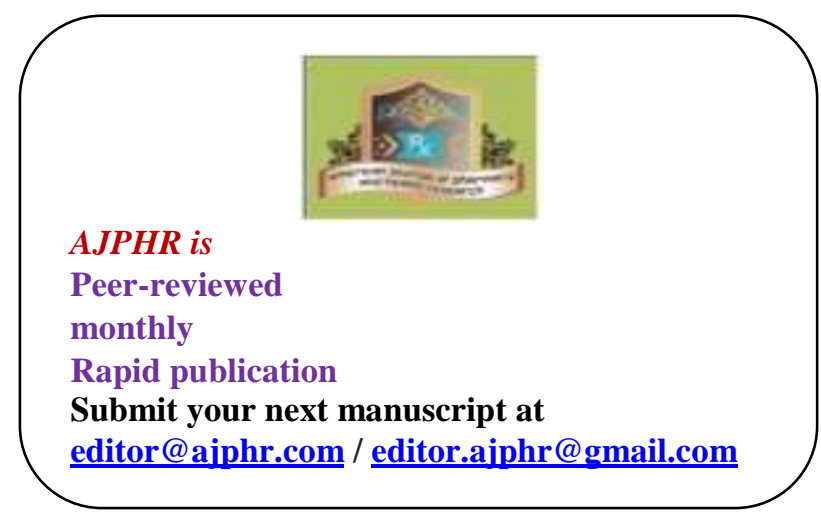

